\section{Research Article}

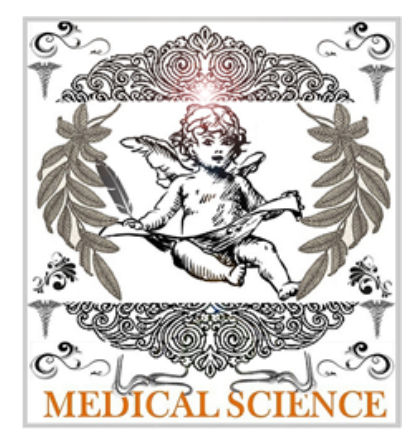

\title{
Application of Binary Regression Analysis in the Prescription Pattern of Antidepressants
}

Banerjee $\mathrm{I}^{1}$, Banerjee $\mathrm{I}^{2}$, Roy $\mathrm{B}^{3}$, Sathian $\mathrm{B}^{4}$

\section{Abstract}

Background: In Nepal several research studies are reported using percentages or cross tabulation method, but the relevance of logistic regression methodology in research is lag behind among the researchers.

Objectives: The main objective of this study was to find the role of logistic regression analysis in the pattern of antidepressants in a tertiary care center in hospitalized patients of Western Nepal.

Methods: A hospital based study was done between 1st October 2009 and 31st March 2010 at Psychiatry Ward of Manipal Teaching Hospital, Nepal. Z test, Chi square test and Binary logistic regression were used for the analysis. We calculated odds ratios (OR) and their $95 \%$ confidence intervals $(95 \% \mathrm{Cl}) \mathrm{P}$-value $<0.05$ was considered to be statistically significant. Different codes were used, the target was coded as 1 and the reference group as 0.

Results: The results of the study were interesting as far as the gender is concerned, male and female patients were $44.7 \%$ and $55.3 \%$ respectively, $95 \% \mathrm{Cl}[28.9,60.5$ and 39.5, 71.1]. Depression was more common in housewives $42.1 \%$. Fluoxetine was the commonest antidepressants to be prescribed $42.1 \%$. Psychiatrists has a tendency of prescribing essential drugs if monthly income $<10000,1.063$ times as compared to monthly income >10000, 2.63 times more in Hindus and 1.197 times more in Brahmins than any other ethnic groups. 9.179 times more tendency of prescribing antidepressants by trade names in case of unemployed patients as compared to employed patients in Nepal.

Conclusion: Binary Logistic regression plays an important role to understand the drug utilization pattern of mood elevators in Western Nepal.

Keywords: Binary Logistic Regression, Depression, Nepal, Psychiatry.

\section{Corresponding Author:}

${ }^{1}$ Lecturer, Department of Pharmacology, Manipal College of Medical Sciences, Pokhara, Nepal.

E-mail: indrajit18@gmail.com

${ }^{2}$ RMO cum Clnical Tutor, Calcutta National Medical College ,Kolkata, West Bengal, India.

${ }^{3}$ Assistant Professor, Department of Physiology, Manipal College of Medical Sciences, Pokhara, Nepal.

${ }^{4}$ Assistant Professor, Department of Community Medicine, Manipal College of Medical Sciences, Pokhara, Nepal.

Full list of author information is available at the end of the article

\section{Background}

It is estimated that unipolar major depression would be the second most leading cause of infirmity after ischemic heart disease in the world by 2020 as compared to the year 1990 it was the fourth leading cause of disability worldwide according to WHO, [1]. A research done in 2010 by Ball et al, in Srilanka, life time ever depression was reported $6.6 \%$ [2]. In major depression, a patient's mood is expressed as depressed, sad, hopeless, and discouraged. The clinical features of major depression are characterized by alteration of appetite or reduction or increase of weight, sleeplessness or hypersomnia, reduced energy, feelings of guilt, inconspicuousness of thoughts, suicidal thoughts, plans or attempts continues for most of the 
day, every day, for at least two weeks [3]. Several research studies are reported using percentages or cross tabulation method because of the unawareness of the relevance of logistic regression methodology among the researchers. The main objective of the study was to find out the role of logistic regression analysis in the prescription pattern of antidepressants.

\section{Material and Methods:}

Study design and the participants: A hospital based observational study was done at Manipal Teaching Hospital, Pokhara, Nepal.

\section{Data collection:}

The study was carried out between 1st October 2009 and 31st March 2010, at Manipal Teaching Hospital in the Psychiatric ward.

The quantitative data consisted of Socio demographic details like age ( $<40$ years and >40years), sex (male and female), occupation (Housewife, teacher, laborer, shopkeeper, student, farmer, retired and others), religion (Hindu, Buddhist, Muslim), ethnicity (Brahmin, Chettri, Newar, Dalit and others), employment (employed and unemployed), monthly Income $(<10000 /$ month and $>10000 /$ month, treatment (Drug monotherapy and drug and psychotherapy, based on essential drug list (essential or non essential), trade/generic, Commonest groups of antidepressants, commonest drug were used were collected.

\section{Coding}

In binary logistic regression, the outcome is coded as 0 and 1.The target is coded as 1 and the reference group as 0 . The codes were used as follows $<40$ yrs. 1 , unemployed patients 1 ,female 1 , Monthly income < 10000 NPR/ month, Religion others 1 , Occupation others 1 and ethnicity others 1.

\section{Inclusion criteria:}

All the patients admitted in psychiatric ward with major depression from 1st October 2009 to 31st March 2010 were included in the study. 38 cases who were seriously ill with severe form of major depression were included in the study.

\section{Exclusion criteria:}

Out of 240 cases who were admitted in the Psychiatry inpatients 202 cases were excluded from the study because we wanted to find the prescription pattern of antidepressants only.
Sample size calculation: For $95 \%$ confidence interval and, significance level $\alpha=5 \%, P=90 \%, Q=10 \%$, allowable error $=$ $11 \%$, required sample size was $35 . P=$ percentage of antidepressants drugs used for the treatment of depression. In the pilot study done prior to the original study with 10 patients were admitted in the psychiatry ward with depression [4].

\section{Outcome Variable:}

Essential drug list of Nepal, generic and trade, treatment (Drug therapy and psychotherapy), groups of antidepressants (newer and typical antidepressants), antidepressants (Fluoxetine, Amitriptyline, Imipramine, Trazodone, Bupropion).

\section{Explanatory variables:}

The demographic and psychiatric disorders were defined at individual level. Factors at individual level were Age, gender, monthly income, employment of the patient.

\section{Data management and statistical analysis:}

Data was analyzed by using Excel 2003, R 2.8.0, SPSS for Windows Version 16.0 (SPSS Inc; Chicago, IL, USA) and EPI Info 3.5.1 Windows Version. The $Z$ test was used to observe the difference between different variables and strength of the relationship with logistic regression. $p<0.05$ is considered as statistically significant. We calculated odds ratios (OR) and their 95\% confidence intervals $(95 \% \mathrm{Cl}) . p<0.05$ is considered as statistically significant $[5,6]$.

\section{Results}

Among the 240 psychiatric patients studied, 38 (15.8\%) cases were suffering from major depression. Male and female patients were $44.7 \%$ and $55.3 \%$ respectively, $95 \% \mathrm{Cl}[28.9,60.5$ and 39.5 , 71.1]. Depression was more common in housewives $42.1 \%$ followed by teachers $18.4 \%$ and students $10.5 \%$. Fluoxetine was the commonest antidepressants to be prescribed $42.1 \%$.

Psychiatrists has a tendency of prescribing essential drugs if monthly income $<10000,1.063$ times as compared to monthly income $>10000,2.63$ times more in Hindus and 1.197 times more in Brahmins than any other ethnic groups. 9.179 times more tendency of prescribing antidepressants by trade names in case of unemployed patients as compared to employed patients in Nepal. Out of 240 cases admitted to the psychiatry ward 130 were male (54.2\%), 95\% Cl [47.9, 60.5] and others were female patients. Most common psychiatric disorder was Schizophrenia $36.3 \%$ followed by Depression and anxiety disorders $15.8 \%$ respectively (Table 1 ). 
Table 1- Binary Logistic regression

\begin{tabular}{|c|c|c|c|c|c|c|}
\hline & & & Essential Drug List & Trade names & Drug monotherapy & Groups of drugs \\
\hline \multirow[t]{2}{*}{ Age } & $>40 \mathrm{yrs}$ & & \multirow[t]{2}{*}{$1.632(0.183-14.573) \times$} & \multirow[t]{2}{*}{$0.07(.007-.719)^{*}$} & \multirow[t]{2}{*}{$0.872(0.081-9.417) \times$} & \multirow[t]{2}{*}{$1.182(0.110-12.651) \times$} \\
\hline & $<40 y r s$ & 1 & & & & \\
\hline \multirow[t]{2}{*}{ Gender } & Male & & \multirow[t]{2}{*}{ - } & \multirow[t]{2}{*}{$0.951(0.060-15.167) \times$} & \multirow[t]{2}{*}{-} & \multirow[t]{2}{*}{-} \\
\hline & Female & 1 & & & & \\
\hline \multirow{2}{*}{$\begin{array}{c}\text { Employment } \\
-\end{array}$} & Employed & & \multirow[t]{2}{*}{-} & \multirow[t]{2}{*}{$9.179(0.395-213.457) \times$} & \multirow[t]{2}{*}{-} & \multirow[t]{2}{*}{-} \\
\hline & Unemployed & 1 & & & & \\
\hline \multirow[t]{2}{*}{$\begin{array}{l}\text { Monthly } \\
\text { Income }\end{array}$} & $\begin{array}{l}<10000 \\
\text { NPR/Month }\end{array}$ & 1 & \multirow[t]{2}{*}{$1.063(0.194-5.841) \times$} & \multirow[t]{2}{*}{$0.105(0.009-1.165) \times$} & \multirow[t]{2}{*}{$0.244(0.024-2.463) \times$} & \multirow[t]{2}{*}{$0.105(0.468-15.41) \times$} \\
\hline & $\begin{array}{c}>10000 \mathrm{NPR} / \mathrm{M} \\
\text { onth }\end{array}$ & & & & & \\
\hline Religion & Others & 1 & $2.630(0.254-27.187) \times$ & $0.270(0.018-4.14) \times$ & $1.070(0.087-13.217) \times$ & $0.912(0.088-9.442) \times$ \\
\hline Occupation & Others & 1 & $0.755(0.43-1.324) \times$ & $1.137(0.720-1.796) \times$ & $1.248(0.805-1.937) \times$ & $0.944(0.552-1.614) \times$ \\
\hline Ethnicity & Others & 1 & $1.197(0.615-2.330) \times$ & $1.378(0.628-3.024) \times$ & $1.095(0.534-2.247) \times$ & $1.5(0.72-3.125) \times$ \\
\hline
\end{tabular}

* $p<0.05$, statistically significant $\times p>0.05$, statistically not significant - $P$ value cannot calculate

\section{Discussion}

\section{Sociodemographic factors and Depression Gender}

In our study it was found that the female patients suffer more from depression than male patient. This finding is similar to a study done in Australia by Mant A et al which has showed that Psychiatric illness was more common in female patients [7]. Similar findings were also found in a study done by Hector $M$ Gonzalez et al. on the use antidepressants among Asians in US in 2010 reveals that Depression is more prevalent in females than in male[8].This could be due to the fact that females has more stressful life events as compared to males.

\section{Occupation}

As far as the occupation was concerned depression was more common in house wife as compared to any other occupation of the patients. It could be due to the fact of stressful life events and the effects of child birth in the housewife can lead to various psychiatric disorders among them [9]. Other reasons could be due to broken families, living apart from their husband or husband residing in foreign countries for employment.

Similar studies has also reported that Psychiatric disorders are more commonly seen in female patients [10 -12].

\section{Prescription pattern of Antidepressants}

In case of antidepressants, most of the cases typical antidepressants were used $76.3 \%$, newer antidepressants were used only in $23.7 \%$ of cases. Among the typical antidepressants Selective serotonin reuptake inhibitors (SSRI's) like Fluoxetine were used in $42.1 \%$ of the cases. Tricyclic antidepressants (TCA) like amitriptyline were used in $26.3 \%$ followed by Imipramine 7.9\%. As far as newer antidepressants are concerned Trazodone were used in $21.1 \%$ and Bupropion were used in $2.6 \%$ of the cases of depression. So it was seen that psychiatrists had trend of prescribing typical antidepressants like serotonin reuptake inhibitors (SSRI's). This finding is dissimilar to a finding done by Raut in India which has found that among the antidepressants Tricyclic antidepressants were commonly used $54 \%$ followed by Selective Serotonin Reuptake Inhibitors were only 36\%[13].

Our findings are similar to a study done on drug utilization of antidepressants in UK done from 1st January 1992 to 31st December 2001 in children and adolescents which showed that a total of 24976 patients received antidepressants. Among the antidepressants Selective serotonin reuptake inhibitors (SSRI's) Fluoxetine $9.89 \%$, was the commonest drug used. Among the Tricyclic antidepressants (TCA) Amitriptiline 5.72\% followed by Imipramine $2.08 \%$ and Nortriptilline $0.52 \%$. Among the newer antidepressants Trazodone $4.68 \%$ was used. Out of which $55.7 \%$ received TCA followed by SSRI's $41.3 \%$ and other antidepressants $2.9 \%$. But the prevalence of the use of TCA has decreased by $30 \%$, whereas the use of SSRI's has increased by 10 folds in the last ten years [14].

\section{Conclusion}

Binary Logistic regression plays an important role to understand the prescription pattern of antidepressants in Western Nepal. 


\section{Abbreviations}

Selective serotonin reuptake inhibitors -SSRI's, Tricyclic antidepressants -TCA, Yrs. Years.

Competing Interests

The authors do not have any conflict of interest arising from the study.

\section{Authors' contribution}

IB designed the study, deduced the data, drafted the manuscript, and revised it. BR and IB2 and planned the study with IB, acquired the data, conducted the data analysis, interpreted the data, and revised the manuscript. IB2 has also participated in the language editing along with IB. BS participated in statistical analysis, interpreted the data, and revised the manuscript. All the authors approved the final document.

\section{Acknowledgments}

I am gratified to Dr. B. M. Nagpal, Dean and CEO, MCOMS, Nepal, Dr. S. M. Banerjee, Orthopedic surgeon, Kalyani, West Bengal, India. I extend our heartfelt and cordial gratitude to LateDr. Akhilesh Chandra Jauhari, Professor, Department of Pharmacology, Manipal College of Medical sciences, Nepal.

\section{Authors Information}

Dr.Indrajit Banerjee MBBS, MD Pharmacology. Currently working as a Lecturer in the Department of Pharmacology, Manipal College of Medical Sciences, Pokhara, Nepal and Chief of Manipal Sanjeevani Clinic. He is the Chief Editor of International Journal of Physiology and Pharmacology (IJPP), Managing Editor of International Journal of Brain Research (IJBR), Section Editor of Nepal Journal of Epidemiology (NJE). He is an Organizing Committee member of International Epidemiological Association Conference 2013 and Confederation of Epidemiological Associations (CEA) Conference December 2013 Organized by Mahatma Gandhi University. He is also Assistant Secretary General of CEA.

Dr.Indraneel Banerjee, MBBS, MS, MRCS. Currently working as RMO cum Clinical Tutor, Calcutta National Medical College, Department of Urology Kolkata, West Bengal, India.

$\mathrm{He}$ is in the editorial board member of IJPP and IJBR.

Mr.Bedanta Roy MSc Physiology. Currently working as Assistant Professor in the Department of Physiology, Manipal College of Medical Sciences, and Pokhara, Nepal. He is at present pursuing $\mathrm{PhD}$ in Neurophysiology. He is the Chief Editor of International Journal of Brain Research (IJBR), Managing editor of International Journal of Physiology and Pharmacology (IJPP), Medical Science 2013;1(1): 19-23

Copyright (C) 2013 CMRA

www.medicalscience.pubmedhouse.com
Section Editor of Nepal Journal of Epidemiology (NJE). He is an Organizing Committee member of International Epidemiological Association Conference 2013 and Confederation of Epidemiological Associations (CEA) Conference December 2013. He is also Assistant Secretary General of CEA.

Dr.Brijesh Sathian MD(AM), PhD. working as Assistant Professor and Bio-statistics Chief in the Department of Community Medicine, Manipal College of Medical Sciences, Pokhara, Nepal. $\mathrm{He}$ is the editorial board member of NJE, IJBS, AIIJMS, GMJ, IJPP, IJBR and Joint Organizing Secretory and treasurer of International Epidemiological Association Conference 2013.Joint Organizing Secretary CEA (Confederation of Epidemiological Associations) Conference December 2013 Organized by Mahatma Gandhi University. He is also the President of CEA.

\section{Reference}

1. Murray CJ, Lopez AD. Evidence-based health policy. Lessons from the Global Burden of Disease Study. Science 1996; 274:740-3.

2. Ball A Harriet, Siribaddana H Sisira, Kovas Y, Glozier N, McGuffin P, Sumathipala A, and Hotopf M.

Epidemiology and symptomatology of depression in Sri Lanka: A cross-sectional population-based survey in Colombo District. J Affect Disord. 2010 June; 123(1-3): 188-196.

3. Mark A. Frye. Bipolar Disorder -A Focus on Depression. The New England Journal of Medicine. 2011; 364:51-9.

4. Sathian B, Sreedharan J, Baboo NS, Sharan K, Abhilash E $\mathrm{S}$, Rajesh E. Relevance of Sample Size Determination in Medical Research. Nepal Journal of Epidemiology 2010; 1(1): 4-10.

5. Sathian B. Reporting dichotomous data using Logistic Regression in Medical Research: The scenario in developing countries. Nepal Journal of Epidemiology 2011;1(4):111-113. 16. Sathian B.

6. Methodological Rigors in Medical Journals From Developing Countries: An Appraisal of the Scenario in Asia. Nepal Journal of Epidemiology 2011; 1(5): 141-43.

7. Mant A, Lansbury G, Bridges-Webb C. Trends in psychotropic drug prescribing in Australia. Med J Aust1987; 146(4):208-10.

8. Hector M. Gonzalez, Wassim Tarraf, Brady T. West, Domin Chan, Patricia Y. Miranda and Fredrick T. Leong. Antidepressant Use among Asians in the United States. Depression and Anxiety. 2010; 27(1): 46-55. 
9. Fahmida A, Wahab MA, Rahman MM: Pattern of psychiatric morbidityamong the patients admitted in a private psychiatric clinic. BangladeshJournal of Medical Science 2009, 8(1-2):23-28.

10. Banerjee I, Roy B, Sathian B, Banerjee I, Chakraborty PK, Saha A. Socio demographic profile and utilization pattern of antipsychotic drugs among schizophrenic inpatients: a cross sectional study from western region of Nepal. BMC Psychiatry. 2013 Mar 22;13:96.

11. Banerjee I, Roy B, Sathian B, Banerjee I, Kumar SS, Saha A: Medications for Anxiety: A Drug utilization study in Psychiatry Inpatients from a Tertiary Care Centre of Western Nepal. Nepal Journal of Epidemiology 2010, 1(4):119-25.

12. Banerjee I, Roy B, Banerjee I, Sathian B, Mondol M, Saha A: Depression and its Cure: A Drug Utilization Study from a Tertiary Care Centre of Western Nepal. Nepal Journal of Epidemiology 2011, 1(5):144-52.

13. Raut $P$. Drug utilization pattern of Psychotropic drugs in Kasturba hospital [dissertation]. Kasturba Medical College: Manipal Univ., 2006.

14. M L Murray, C S de Vries, I C K Wong; A drug utilisation study of antidepressants in children and adolescents using the General Practice Research Database; Arch Dis Child 2004;89:1098-1102.

Information about the article:

Received on 12.3.2013

Accepted on 17.4.2013

Published on 30.5.2013

Submit your next manuscript to Medical Science and take full advantage of:

- Expedient online submission

- Thorough peer review

- No Publication fee

- No space limitations or color figure charges

- Immediate publication after acceptance

- Research which is freely available for redistribution

Submit your manuscript at medicalscience@pubmedhouse.com 